\title{
Revenue and Attendance Simultaneous Optimization in Performing Arts Organizations
}

\author{
Baldin, Andrea; Bille, Trine; Ellero, Andrea; Favaretto, Daniela
}

\author{
Document Version \\ Accepted author manuscript \\ Published in: \\ Journal of Cultural Economics \\ DOI: \\ $10.1007 / \mathrm{s} 10824-018-9323-7$ \\ Publication date: \\ 2018 \\ License \\ Unspecified
}

Citation for published version (APA):

Baldin, A., Bille, T., Ellero, A., \& Favaretto, D. (2018). Revenue and Attendance Simultaneous Optimization in Performing Arts Organizations. Journal of Cultural Economics, 42(4), 677-700. https://doi.org/10.1007/s10824018-9323-7

Link to publication in CBS Research Portal

\section{General rights}

Copyright and moral rights for the publications made accessible in the public portal are retained by the authors and/or other copyright owners and it is a condition of accessing publications that users recognise and abide by the legal requirements associated with these rights.

\section{Take down policy}

If you believe that this document breaches copyright please contact us (research.lib@cbs.dk) providing details, and we will remove access to the work immediately and investigate your claim. 


\title{
Revenue and Attendance Simultaneous Optimization in Performing Arts Organizations Andrea Baldin, Trine Bille, Andrea Ellero, and Daniela Favaretto
}

\author{
Journal article (Accepted version*)
}

\section{Please cite this article as:}

Baldin, A., Bille, T., Ellero, A., \& Favaretto, D. (2018). Revenue and Attendance Simultaneous Optimization in Performing Arts Organizations. Journal of Cultural Economics, 42(4), 677-700. https://doi.org/10.1007/s10824-018-9323-7

This is a post-peer-review, pre-copyedit version of an article published in Journal of Cultural Economics. The final authenticated version is available online at:

DOl: https://doi.org/10.1007/s10824-018-9323-7

* This version of the article has been accepted for publication and undergone full peer review but has not been through the copyediting, typesetting, pagination and proofreading process, which may lead to differences between this version and the publisher's final version AKA Version of Record. 


\title{
Revenue and attendance simultaneous optimization in performing arts organizations
}

Received: date / Accepted: date

\begin{abstract}
Performing arts organizations are characterized by different objectives other than revenue. Even if, on the one hand, theaters aim to increase revenue from box office as a consequence of the systematic reduction of public funds; on the other hand they pursue the objective to increase its attendance. A common practice by theaters is to provide incentives to customers to discriminate among themselves according to their reservation price, offering a schedule of different prices corresponding to different seats in the venue. In this context, price and allocation of the theater seating area are decision variables that allow theater managers to manage their two conflicting goals to be pursued. In this paper we introduce a multi-objective optimization model that jointly considers pricing and seat allocation. The framework proposed integrates a choice model estimated by multinomial logit model and the demand forecast, taking into account the impact of heterogeneity among customer categories in both choice and demand. The proposed model is validated with booking data referring to the Royal Danish theater during the period 2010-2015.
\end{abstract}

Keywords Multi-objective optimization · Pricing · Seat allocation · Multinomial logit model $\cdot$ theater demand

JEL Classification: C35; C61; L11; Z11

\section{Introduction}

In the seminal article by Baumol and Bowen (1966) the authors claim how theaters will be more and more dependent on subsidies, due to their productivity lag. However, the last decades' tendency shows that public funds allocated to non profit performing arts organizations in Western countries (Marco-Serrano, 
2006) are decreasing ${ }^{1}$. This fact has forced theaters to increase other sources of revenue, including box office revenue. In addition, such organizations pursue the aim to increase the attendance, for a couple of reasons: first, they feel the mission is to spread culture as broad as possible (Hansmann, 1981) legitimizing their social value; second, they prefer to avoid empty seats in the venue that can have a negative effect on the reputation of the theater.

In this context, managers of the performing arts organizations can implement Revenue Management (RM) techniques (see e.g.Talluri and Van Ryzin (2006)) in order to balance between the rate of occupancy and the profitability of theater. The most common among these techniques is realized through market segmentation based on the price leverage, that leads to different pricing schemes. For instance, price reductions are offered to customers' segments, such as students and senior citizens, who are supposed to look for more affordable prices. Discounts are offered also to those customers - subscribers who buy in advance a bundle of tickets, assuring a long-term commitment towards the theater. Due to heterogeneity in price sensibility within the same customer segment, one usual practice applied by theaters is to use a non-linear tariff system offering a schedule of different prices according to the quality of the product. In this case, different prices are charged according to the seat location in the venue in order to better capture consumers' willingness to pay. Indeed, this mechanism incentivizes customers to discriminate by themselves in choosing the seating area they prefer. So, beside the pricing strategy, also the seat allocation across these fare classes (i.e seating area) represents a decision that may encourage an orientation of the theater towards either the maximization of the total attendance or the maximization of revenue. In the first case, we expect that theater would increase the accessibility of the most expensive seating areas for all the customers: to do this, it is convenient to propose a scheme in which the prices of the different seating areas are closer downward. This scheme will lead to an increase of the size of the expensive seating area and, in addition, can favour a customer buy-up behavior (i.e buying a ticket for a more expensive fare class when the ticket for the required seating area is not available). In the second case, we expect that theater would strengthen the self-discrimination operated by customers. Thus, the allocation policy will strongly depend on the type of customer attending the performance: if the performance attracts an audience group (as young customers) that is supposed to be highly price sensitive, the theater would enlarge the cheapest seating area in order to prevent a loss in revenue. In the opposite case, the theater would take advantage of the inelastic demand by enlarging the expensive seating area.

Considering this pricing and allocation strategy, not only the demand forecasting becomes essential, but also the understanding of the customers' behavior with respect to price discrimination by seating area. Since the paper by Tal-

\footnotetext{
1 This framework holds also for our case study: the Royal Danish theater. According to the National Danish Statistics (http://www.statbank.dk), the public subsidy to the Royal Danish theater decreases from 608675 Danish crowns in the 2011/2012 season, to 573900 Danish crowns in the $2014 / 2015$ season.
} 
luri and Van Ryzin (2004), discrete choice models have emerged as a standard approach to incorporate the buy-up and buy-down behavior.

This paper proposes an optimization model that considers the pricing and allocation problem in the performing arts context. To this end, the demand forecasting is integrated with a customer choice model. In order to accomodate for heterogeneity in preference over seating areas, we adopt a multinomial logit model (MNL) using customer's characteristics and performance-production attributes as variables to be interacted with the characteristics of the choice alternatives.

Our model has been implemented to a data set provided by the Royal Danish theater which refers to the period 2010-2015. A simulation is conducted considering three performances that differ from each other by characteristics affecting the demand.

The remainder of the paper is organized as follows: Section 2 presents the relevant literature on demand-management decisions in the performing arts context; Section 3 describes the research framework, whereas Section 4 and Section 5 present respectively the demand estimation and the choice model. Section 6 describes the optimization model, whereas Section 7 presents the results of our simulation. Finally Section 8 provides some conclusions.

\section{Literature review}

The literature of cultural economics has been dealing with the objectives of performing arts institutions. Since most performing arts institutions are nonprofit firms, this taps into a more general literature on the objectives of nonprofit firms (e.g. Hansmann (1980) and Steinberg (1986)). Steinberg (1986) suggests that nonprofit firms are either service maximizers or budget maximizers or something in between. However, in the performing arts, the concept of service is not straightforward. Several authors (e.g. Throsby et al (1993), Throsby (1994) and Hansmann (1981)) have suggested three different measures of output: 1) Quality, 2) Audience size and 3) Budget. Several empirical studies have shown that the performing arts are primarily output maximizers (either quality or quantity), and less budget maximizers (see e.g. Luksetich and Lange (1995); and Gapinski et al (1985)). For an overview of the literature, see Brooks (2006). To our knowledge, no studies have been made dealing with the optimization decisions in the performing arts when the repertoire is planned (based on quality decisions), while the theater wants to make the optimal decision on how to maximize attendance as well as revenue, basing this decision on prices and seat categories.

Most of the research related to the demand-management decision in the theater sector has focused on the price discrimination practice. Hansmann (1981) claims that in the nonprofit performing arts sector, price discrimination is not effective due to the difficulty of identifying customers with inelastic demand. Therefore, according to the author, the only form of discrimination that nonprofit enterprises can apply is by asking for a voluntary donation, in order to 
extract a part of consumer's surplus. Seaman (1985) raises some doubts about Hansmann (1981) hypotheses: the author measures the degree of price discrimination (such as: the number of different prices charged and the standard deviation of the prices charged) to a set of nonprofit performing art organizations. He concludes that price discrimination varies significantly across art forms (opera, ballet, theater, symphony concert) and that the organizations that discriminate more are characterized by a high ratio between fixed cost and attendance. Huntington (1993) justifies the adoption of price discrimination by seating area, by referring to Rosen's utility model (i.e. the hedonic price model, see Rosen (1974)), as there are observable differences between different seats. Moreover, the author compares the box office revenue between theaters operating a single price policy and those operating a discrimination pricing policy: he finds that the price range policy is statistically significant and positively correlated with the revenue of the theater, controlling for seat capacity and the number of performances per year. Rosen and Rosenfield (1997) describe a model in which theater venue has two types of seats: (high and low quality), and the theater manager knows the distribution of reservation price for both seat category. First, the authors solve the pricing problem, given the quantity of seats for each category. Second, the authors solves the allocation problem, given the optimal pricing policy. Leslie (2004) considers the Broadway show "Seven Guitars" and estimates a structural econometric model of price discrimination based on an individual consumer behavior model, that incorporates all the types of price discrimination (by seating area and social category). The model allows him to perform different experiments using alternative pricing policies. Tereyagoglu et al (2012) use the data from the ticket purchase transactions of the shows of a symphony orchestra in the northeast region of the US, in order to employ a proportional hazard framework to analyze how pricing and discount actions affect the timing of customers purchase over time.

\section{Research framework}

\subsection{The Royal Danish theater}

The Royal Danish theater was founded in 1748 and is the Danish national theater. It has three main Stages in Copenhagen. The Old Stage from 1874, a new Royal Opera House from 2005 and a new Royal Playhouse from 2008. The Opera House and the Playhouse have a main stage and smaller stages for experimental productions. It is one of the few theaters in the world offering both opera, ballet and theater performances as well as classical concerts. Today, The Old Stage is the house where ballet is performed.

The law of the Royal Danish theater states that it is the national theater for the whole country and the entire population. Besides, it has an obligation to produce a broad repertoire of high artistic quality among ballet, opera and plays. It is required to continue the classical traditions as well as developing 
the performing arts in new and contemporary ways, with a special attention on productions of Danish origin.

The Royal Danish theater is on the state budget under the Ministry of Culture, and has a number of more specific obligations in agreement with the current Minister of Culture. Included in these obligations, there are general cultural policy goals, such as having special productions for children and youth, and keeping prices to a level that makes the theater accessible for all socio-economic groups.

In 2015, the theater had a total budget of 705,4 million DKK (94 million Euros), of which 76 percent were public support from the Government. The theater had 165,8 million DKK (22 million Euros) in own earnings, of which 69 percent (15 million Euros) was from ticket sales, the rest was income from sponsors etc.

Due to its obligations as a national theater, it has to decide its repertoire based on a number of parameters, namely quality and variety, understood as a fairly large number of different productions from the classical repertoire as well as new productions, developing the performing arts, of Danish as well as international productions. In addition, it has to decide the number of performances of each production during the season and how they are scheduled on weekdays and weekends. It should be noticed that when a given production is played less than demanded by the audience as well as if a performance is played more times than demanded, it will create a loss in earnings. Moreover, there are high fixed costs in taking a new producing on stage (due to rehearsal time, designing the staging etc.), while the costs of prolonging a production with extra performances are small, and the marginal costs are lower than the marginal revenue (Hansen, 1991).

Finally, the theater has also to decide its price policy, including price differentiation based on different audience groups (like young, senior people and subscribers) as well as seat categories, time of the performance, the type of the performance, the production costs etc.

\subsection{Problem description}

In this paper, we assume that the repertoire decisions are already determined by the theater, both with regard to the variety of productions and the number of performances of each production during a season. With this assumption the theater has to decide on the price and the allocation of seat categories for the individual performances. It is assumed that the theater wants to optimize both attendance and revenue, where the former finds an upper limit in the theater capacity. Thus we will consider a bi-objective optimization model that incorporates the demand forecast and the customers' seat choice model. The latter is estimated with a multinomial logit (MNL) model that predicts the probability to choose a particular seating area as a function of price and performance characteristics. From Baldin and Bille (2017) we know that some 
audience groups (especially young people) are quite price sensitive, while other groups are very insensitive to price (e.g., subscribers). Therefore, we estimate one demand forecast for each customer category; whereas the choice model accounts for heterogeneity by including choice-invariant variables that account also for the customer category.

The methodological procedure in this paper follows the study by Hetrakul and Cirillo (2014) that proposes, in a railway setting, an optimization model in which discrete choice models and demand function are integrated, in order to calculate the price and fraction of the demand to be accepted for each origin-destination pair.

\section{Demand forecast}

\subsection{Sample selection}

The demand estimation is based on booking data from the sale system of the Royal Danish theater for the period 2010/2011 to 2014/2015. The sample consists of 401 opera performances which took place during that period. We estimate a demand function for each identified customer category, with which we refer to the price type applied by the theater in the price discrimination process across buyers. Hence, we assume that the market segmentation is solely based on the price leverage. Among the numerous existing price types (including customers with a loyalty card, employees, group sales, disabled...), we consider the three main customer categories that together account for nearly $80 \%$ of the total tickets sold: standard ticket buyers $(45.9 \%)$ who pay the full price for the ticket; youngs (under 25 years)-student customers (6.1\%) for which tickets are discounted by $50 \%$; and subscribers (26.1\%). Regarding the subscribers categories, Royal Danish theater applies two types of subscriptions: a fixed subscription, in which the bundle of events included is predetermined by the theater, and a "choose your own" subscription that allows the customers to choose the productions they want to see. In the first case, a discount of $15 \%$ is applied, whereas in the second case the discount drops to $10 \%$. In order to simplify the optimization model, we merge the two types of subscriptions, considering the average discount of $12.5 \%$. In this category we include also the additional tickets that a subscriber can purchase, besides his subscription. For example, when a subscriber buys a performance ticket of a production that it is not included in the subscription, this ticket is also discounted by $10 \%$.

For the purpose of model simplicity, there are some remarkable categories that, given their low number of attendees per performance, are not considered. For example, tickets for senior customers, who are entitled to a discount of $50 \%$, represent only $2.5 \%$ of the tickets since this discount is made available only for some performances decided by theater management. Indeed, as many senior customers are subscribers, it is not convenient to offer this discount for all the performances. We exclude also the young/student subscribers, who ac- 
count for $0.74 \%$ of the total theater market: their discount is $65 \%$ for a fixed subscription and $60 \%$ for a "choose your own" subscription.

\subsection{Demand estimation}

Following the literature, we adopt a double-log specification, which is the most popular functional form adopted in estimating theater-attendance demand (Seaman, 2006). For each category $j$, the following demand function is estimated:

$$
\ln \left(D_{j}\right)=\alpha_{j}+\beta_{j} \ln \left(p_{j}\right)+\gamma_{j}^{\prime} z+\epsilon_{j}
$$

so as:

$$
D_{j}=\exp \left(\alpha_{j}+\beta_{j} \ln \left(p_{j}\right)+\gamma_{j}^{\prime} z+\epsilon_{j}\right)
$$

where, for a given performance, $D_{j}$ is the number of tickets sold to category $j, p_{j}$ is the ticket average price of deflated by $\mathrm{CPI}^{2}$ charged to category $j$ : in particular, we take the average price of the different seat categories offered by the theaters. $z$ is a vector of performance and production characteristics, while $\epsilon_{j}$ is an error term.

Concerning the performances scheduling, we include three dummy variables to take into account the weekly seasonal effect: WKDAY denotes performances run during weekdays (from Monday morning to Friday morning); WKEND indicates performances run during Friday and Saturday evenings or during the evening before a public holiday. Finally SUNDAY denotes performances that take place on Sunday or in a public holiday. This latter group of performances are "matinée" as no evening performances take place on Sunday. Besides Sundays, in the other days of the week, performances can take place either on monday-afternoon or during the evening. We denote with EVE performances that take place during the evening.

In order to capture the seasonality effect, we construct monthly dummy variables for each month of the year, except for July and August when the theater is closed.

In addition, following Corning and Levy (2002) we also include REMAIN and TOTPERF denoting respectively the number of remaining and total perfomances of a given production. We also find a significant interaction between these two variables: indeed, this interaction term allows to weigh the amount of remaining performance with respect to the total number of performances. We also control for the production characteristics: to capture the popularity of an opera show, we introduce the variable POP measured as the number of times the production is performed worldwide during the same year it has been performed at the Royal Danish theater ${ }^{3}$. However, it should be considered that some Danish productions (e.g Maskarade, Livlagens besøg) are popular in Denmark but not worldwide. To control for this aspect, we include

\footnotetext{
2 CPI data are collected by Statistics Denmark: http://www.dst.dk/en

3 We collect these data through "Operabase", a website designed to collect statistics about operatic activity worldwide: http://operabase.com
} 
the dummy variable DANISH, denoting Danish productions. Moreover, the dummy variable NEWDKT controls for productions that take place for the first time at Royal Danish theater.

We also control for the year in which the production was created by introducing three dummies: 1920-2015, 1850-1919, BEFORE 1850.

As our analysis is based on performances running throughout 5 years, we include a time trend variable $t$. Finally, considering that the total capacity of the theater can change due to production requirements, we add the variable CAPACITY indicating the number of the available seats for a specific show. In estimating the demand function for subscribers, we add a new variable SUBYEAR indicating the log number of subscribers in the current season. In fact, subscriptions are sold in advance and the number of subscribers is known to the theater before the season starts. However, given a production, it is unknown which is the distribution among performances of customers who buy a fixed subscriptions.

Table 1 provides a descriptive statistics of the data.

\begin{tabular}{|c|c|c|c|c|}
\hline Variable & Mean & SD & Min & $\operatorname{Max}$ \\
\hline Price (standard ticket) & 456.06 & 74.93 & 208.96 & 661.13 \\
\hline Standard tickets sold & 562.34 & 252.11 & 62 & 1117 \\
\hline Young tickets sold & 73.46 & 63.65 & 0 & 576 \\
\hline Subscribers ticket sold & 310.33 & 151.37 & 0 & 716 \\
\hline REMAIN & 7.49 & 5.38 & 1 & 30 \\
\hline TOTPERF & 14 & 6.07 & 6 & 30 \\
\hline CAPACITY & 1482.89 & 45.51 & 1297 & 1529 \\
\hline $\mathrm{POP}$ & 213.17 & 186.00 & 1 & 507 \\
\hline SUNDAY & 0.174 & 0.380 & 0 & 1 \\
\hline WKEND & 0.257 & 0.437 & 0 & 1 \\
\hline WKDAY & 0.568 & 0.496 & 0 & 1 \\
\hline EVE & 0.733 & 0.443 & 0 & 1 \\
\hline JANUARY & 0.157 & 0.364 & 0 & 1 \\
\hline FEBRUARY & 0.117 & 0.322 & 0 & 1 \\
\hline MARCH & 0.149 & 0.357 & 0 & 1 \\
\hline APRIL & 0.115 & 0.319 & 0 & 1 \\
\hline MAY & 0.147 & 0.355 & 0 & 1 \\
\hline JUNE & 0.047 & 0.2127 & 0 & 1 \\
\hline SEPTEMBER & 0.027 & 0.163 & 0 & 1 \\
\hline OCTOBER & 0.085 & 0.279 & 0 & 1 \\
\hline NOVEMBER & 0.125 & 0.331 & 0 & 1 \\
\hline DECEMBER & 0.030 & 0.171 & 0 & 1 \\
\hline $1920-2015$ & 0.160 & 0.366 & 0 & 1 \\
\hline $1850-1919$ & 0.486 & 0.500 & 0 & 1 \\
\hline BEFORE 1850 & 0.354 & 0.479 & 0 & 1 \\
\hline DANISH & 0.027 & 0.163 & 0 & 1 \\
\hline NEW DKT & 0.651 & 0.477 & 0 & 1 \\
\hline$t$ & 3.06 & 1.295 & 1 & 5 \\
\hline
\end{tabular}

401 observations

Table 1: Descriptive statistics of OLS variables 
We estimate (1) by OLS with robust standard-error. Although more sophisticated models are available for a forecast analysis (Ainslie et al (2005)), such techniques do not necessarily provide a significant improvement (Andrews et al, 2008); (Eliashberg et al, 2009).

We also have checked for multicollinearity issues that do not seem to arise. Table 2 shows the estimation results of the demand function for all the categories considered.

Results of the demand estimation reveal that price elasticity differs across customer categories. Young customers is the most price sensitive audience group: a $1 \%$ increase in ticket price results in approximately $1.84 \%$ decline in quantity demanded. Standard ticket buyers are less price sensitive as the price elasticity is less than unity: a $1 \%$ increase in ticket price results in approximately $0.49 \%$ decline in quantity demanded . As with previous results in literature show (Felton, 1994); (Baldin and Bille, 2017), subscribers are the least price sensitive: in our sample, the price coefficient is even not statistically significative. This result is not surprising as literature has shown in some cases even a positive price elasticity in the demand for performing arts, identifying the theatrical experience as a Veblen good (Laamanen, 2013).

The results for the single ticket buyers show a strong explanatory power $\left(R^{2}=0.75\right)$ and almost all variables are statistically significant. In particular, Table 2 shows that, for this type of customers, the demand is higher for Friday/Saturday evening performances. The number of times a title is rerun (TOTPERF), which is supposed to be an indicator of the total expected demand for that production, has a positive impact on the demand for a single performance. Moreover, given the same production, each performance has a $5.75 \%$ higher demand than the previous, keeping fixed the number of times a performance is rerun. This is probably due to a word-of-mouth effect (Laamanen, 2013). Furthermore, we can deduce that single ticket buyers prefer traditional and less risky productions than the more experimental ones: indeed the productions that take place for the first time at Royal Danish theater have a negative impact on demand; whereas popular score has a positive impact, as well as those productions composed before 1919 .

Results for young customers and subscribers have a lower explanatory power $\left(R^{2}\right.$ is respectively 0.42 and 0.38 ). For the former, there is a positive wordof-mouth and time trend effect. Furthermore, the Danish productions have a strong positive effect on demand, as well as the popular of the production worldwide; but also the productions that take place for the first time at Royal Danish theater seem to be appealing to young customers.

Concerning subscribers, we note a significant month-seasonality and time trend effect. Contrary to single ticket buyers, subscribers seem to appreciate less conventional productions, as the coefficient associated with the popular score is negative. On the other side, productions composed before 1850 seem to be preferred by this audience group.

Table 3 compares the actual attendance with the values predicted by the demand functions. The prediction capability of the model is measured with different indicators, such as root mean squared error, mean absolute error, average 


\begin{tabular}{|c|c|c|c|}
\hline Variable & Single tickets & Young & Subscribers \\
\hline Intercept & $\begin{array}{l}2.3538^{* *} \\
(1.017)\end{array}$ & $\begin{array}{l}6.7917^{* * * *} \\
(1.986)\end{array}$ & $\begin{array}{l}-0.1729 \\
(3.1428)\end{array}$ \\
\hline Log price & $\begin{array}{l}-0.4904^{* * *} \\
(0.1811)\end{array}$ & $\begin{array}{l}-1.8440^{* * * * *} \\
(0.3994)\end{array}$ & $\begin{array}{l}-0.1315 \\
(0.7346)\end{array}$ \\
\hline SUNDAY & $\begin{array}{l}0.22741^{* * * * *} \\
(0.0654)\end{array}$ & $\begin{array}{l}-0.0459 \\
(0.1321)\end{array}$ & $\begin{array}{l}0.2652 \\
(0.1980)\end{array}$ \\
\hline WKEND & $\begin{array}{l}0.4620^{* * * *} \\
(0.0357)\end{array}$ & $\begin{array}{l}0.0083 \\
(0.0644)\end{array}$ & $\begin{array}{l}-0.0338 \\
(0.0926)\end{array}$ \\
\hline EVE & $\begin{array}{l}-0.1205^{* *} \\
(0.0596)\end{array}$ & $\begin{array}{l}-0.0220 \\
(0.1106)\end{array}$ & $\begin{array}{l}0.1626 \\
(0.1838)\end{array}$ \\
\hline REMAIN & $\begin{array}{l}-0.0575^{* * * *} \\
(0.0089)\end{array}$ & $\begin{array}{l}-0.0483^{* * *} \\
(0.0173)\end{array}$ & $\begin{array}{l}-0.0122 \\
(0.0249)\end{array}$ \\
\hline TOTPERF & $\begin{array}{l}0.0365^{* * * *} \\
(0.0049)\end{array}$ & $\begin{array}{l}-0.0081 \\
(0.0097)\end{array}$ & $\begin{array}{l}-0.0472^{* * *} \\
(0.0154)\end{array}$ \\
\hline REMAIN x TOTPERF & $\begin{array}{l}0.0020^{* * * *} \\
(0.0004)\end{array}$ & $\begin{array}{l}0.0018^{* *} \\
(0.0007\end{array}$ & $\begin{array}{l}0.0013 \\
(0.0009)\end{array}$ \\
\hline JANUARY & $\begin{array}{l}0.2743^{*} \\
(0.1603)\end{array}$ & $\begin{array}{l}-0.0458 \\
(0.2493)\end{array}$ & $\begin{array}{l}1.0828^{* *} \\
(0.5359)\end{array}$ \\
\hline FEBRUARY & $\begin{array}{c}0.3370^{* *} \\
(0.1590)\end{array}$ & $\begin{array}{l}0.1374 \\
(0.2415)\end{array}$ & $\begin{array}{l}1.1611^{* *} \\
(0.5034)\end{array}$ \\
\hline MARCH & $\begin{array}{l}0.3383^{* *} \\
(0.1568)\end{array}$ & $\begin{array}{l}-0.0316 \\
(0.2350)\end{array}$ & $\begin{array}{l}1.2604^{* *} \\
(0.4980)\end{array}$ \\
\hline APRIL & $\begin{array}{l}0.4957^{* * *} \\
(0.1580)\end{array}$ & $\begin{array}{l}-0.0492 \\
(0.2384)\end{array}$ & $\begin{array}{l}1.2728^{* *} \\
(0.5195)\end{array}$ \\
\hline MAY & $\begin{array}{l}0.5726^{* * * *} \\
(0.1542)\end{array}$ & $\begin{array}{l}-0.1028 \\
(0.2318)\end{array}$ & $\begin{array}{l}1.3395^{* * *} \\
(0.5044)\end{array}$ \\
\hline JUNE & $\begin{array}{l}0.5192^{* * *} \\
(0.1631)\end{array}$ & $\begin{array}{l}-0.2148 \\
(0.2764)\end{array}$ & $\begin{array}{l}1.1711^{* *} \\
(0.4956)\end{array}$ \\
\hline SEPTEMBER & $\begin{array}{l}-0.2083 \\
(0.1949)\end{array}$ & $\begin{array}{l}-0.9979^{* * *} \\
(0.3619)\end{array}$ & $\begin{array}{l}1.5058^{* * *} \\
(0.5473)\end{array}$ \\
\hline OCTOBER & $\begin{array}{l}0.0237 \\
(0.1597)\end{array}$ & $\begin{array}{l}-0.3690 \\
(0.2449)\end{array}$ & $\begin{array}{l}1.3119^{* * *} \\
(0.5255)\end{array}$ \\
\hline NOVEMBER & $\begin{array}{l}0.0575 \\
(0.1554)\end{array}$ & $\begin{array}{l}-0.2394 \\
(0.2315)\end{array}$ & $\begin{array}{l}1.0168^{* *} \\
(0.5030)\end{array}$ \\
\hline POP & $\begin{array}{l}0.0007^{* * * *} \\
(0.0001)\end{array}$ & $\begin{array}{l}0.0022^{* * * *} \\
(0.0002)\end{array}$ & $\begin{array}{l}-0.0013^{* * * *} \\
(0.0002)\end{array}$ \\
\hline $1850-1919$ & $\begin{array}{l}0.6935^{* * * *} \\
(0.0758)\end{array}$ & $\begin{array}{l}0.1236 \\
(0.1903)\end{array}$ & $\begin{array}{l}0.6683^{* * *} \\
(0.2374)\end{array}$ \\
\hline BEFORE 1850 & $\begin{array}{l}0.6385^{* * * *} \\
(0.0743)\end{array}$ & $\begin{array}{l}0.1108 \\
(0.1851)\end{array}$ & $\begin{array}{l}0.8165^{* * * * *} \\
(0.2292)\end{array}$ \\
\hline DANISH & $\begin{array}{l}-0.1132 \\
(0.0858)\end{array}$ & $\begin{array}{l}0.8734^{* * * *} \\
(0.1247)\end{array}$ & $\begin{array}{l}-0.5989^{* * *} \\
(0.1997)\end{array}$ \\
\hline NEWDKT & $\begin{array}{l}-0.0648^{*} \\
(0.0376)\end{array}$ & $\begin{array}{l}0.1970^{* * *} \\
(0.0771)\end{array}$ & $\begin{array}{l}-0.0524 \\
(0.0774)\end{array}$ \\
\hline CAPACITY & $\begin{array}{l}0.0037^{* * * *} \\
(0.0004)\end{array}$ & $\begin{array}{l}0.0045^{* * * *} \\
(0.0009)\end{array}$ & $\begin{array}{l}0.0008 \\
(0.0010)\end{array}$ \\
\hline$t$ & $\begin{array}{l}-0.0101 \\
(0.0164)\end{array}$ & $\begin{array}{l}0.0606^{* *} \\
(0.0303)\end{array}$ & $\begin{array}{l}0.1007^{* *} \\
(0.0508)\end{array}$ \\
\hline SUBYEAR & & & $\begin{array}{l}0.5192^{* * * *} \\
(0.1348)\end{array}$ \\
\hline R-square & 0.7512 & 0.4213 & 0.3830 \\
\hline Model F-value & $51.64^{* * * *}$ & $13.22^{* * * *}$ & $5.02^{* * * *}$ \\
\hline No. of observations & 401 & 401 & 401 \\
\hline
\end{tabular}

Robust st.error listed under coefficients

${ }^{* * * *} p<0.001{ }^{* * *} p<0.01{ }^{* *} p<0.05^{*} p<0.10$

Table 2: Estimation results of demand functions 
error and Pearson correlation between predicted and actual. In addition, we perform the out of sample validation. We consider 74 performances run during season 2015/2016 that are not included in our sample. The demand functions for such performances are estimated using the coefficients obtained for our initial sample, and their final estimations are compared with the actual attendance.

Whereas the average errors are decidedly higher for the out of sample performances than the sample performances; the other measures are similar among the two groups of performances.

\begin{tabular}{lrrrr}
\hline & $\begin{array}{r}\text { Root mean } \\
\text { squared errors }\end{array}$ & $\begin{array}{r}\text { Mean absolute } \\
\text { errors }\end{array}$ & $\begin{array}{r}\text { Pearson } \\
\text { correlation }\end{array}$ & $\begin{array}{r}\text { Average } \\
\text { errors }\end{array}$ \\
$2010 / 2011-2014 / 2015$ & 148.33 & 114.55 & 0.78 & 12.76 \\
Single tickets & 52.09 & 28.36 & 0.68 & 9.92 \\
Young & 139.22 & 106.44 & 0.56 & 26.20 \\
Subscribers & & & & \\
\hline $2015 / 2016$ & 155.31 & 133.06 & 0.83 & -86.11 \\
\hline Single tickets & 53.52 & 30.69 & 0.56 & 12.11 \\
Young & 111.02 & 100.84 & 0.57 & -33.58 \\
Subscribers & & & & \\
\hline
\end{tabular}

Table 3: Predictive performance of the demand functions

\section{Customer choice model}

\subsection{Sample selection}

The choice model concerns the price discrimination across seating areas. The theater policy has been refined in the last years. In 2010, the OperaHouse offered 5 different price zones, 6 price zones in 2011 and 8 seating areas from 2012 onwards (Figure 1).

The subdivision is not physically evident: for example, zone called "price A" includes both stall seats and first balcony seats; whereas zone called "price B" includes stall seats as well as first and second balcony seats, and so forth. This allows the theater manager to be quite flexible in the subdivision of the venue. Since the number of price zones changed during the period under examination, we aggregated productions with more than five price zones into five seat categories. The procedure adopted follows Baldin and Bille (2017), to which we refer for details.

For logistic reasons, it has not been possible to collect data for the choice model estimation for the whole sample considered in the demand function. 


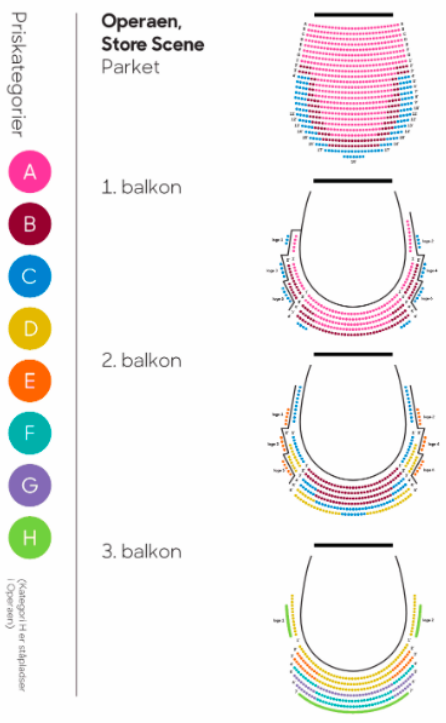

Fig. 1: Price zones at the Opera House. Source: https://kglteater.dk/en/

Our sample consists in 103322 bookings which involve 11 opera productions and 122 performances.

\subsection{Estimation of seat choice}

After estimating the demand for each performance, in this section we propose a choice model for the seating area decision. To this aim, we adopt a multinomial logit (MNL) approach. Hence, we assume that each customer chooses the seat that maximizes her utility. The independent variables that enter in the model as the attributes of each choice are: price and a dummy variable for each seat category. These variables aim to capture the tradeoff behavior between cheap seats with low visibility and/or acoustics, and more expensive high quality seats. Moreover, in order to address heterogeneity, we allow the price sensitivity and the marginal utility of the seating areas to vary across customer categories. The price coefficient also interacts with variables related to the performance characteristics.

The utility of a customer that buys a ticket which refers to the seating area $s$, for the performance $i$, can be formulated as:

$$
U_{s j}=V_{s j}+\epsilon_{s j}
$$

with

$$
V_{s j}=p_{s j} \cdot\left(\beta_{1}+\beta_{2} \cdot \text { young }+\beta_{3} \cdot s u b+\gamma^{\prime} z\right)+\operatorname{seat}_{s} \cdot\left(\delta_{1}+\delta_{2} \cdot \text { young }+\delta_{3} \cdot s u b\right)
$$


where young and sub are dummy variables denoting whether the customer is respectively a young customer or a subscriber. This implies that single ticket buyers are treated as the base category, and $z$ is a vector of performance and production characteristics. In our estimation, such characteristics are represented by the dummy variables SUNDAY and WEEKEND, already defined in the demand function. Moreover, we used the number of times the production is performed worldwide during the same year, to define three dummy variables denoting the degree of popular of the production: Low popular (for productions run less than 50 times worldwide) treated as base variable; Medium popular (for productions run between 50 and 150 times worldwide) and High popular (for productions run more than 150 times worldwide). Finally seat s $_{\text {is }}$ a dummy variable denoting whether the seat belongs to area $s$ or not. Seat 1 is used as baseline in order to guarantee the identification of the model.

Assuming that the error components in (3) are independent and identically distributed according to a Gumbel distribution, the probability of a customer belonging to category $j$ purchasing a ticket of seating area $s$ (among the 5 seating areas) is given by:

$$
\operatorname{Pr}(s \mid j)=\frac{\exp \left[V_{s j}\right]}{\sum_{t=1}^{5} \exp \left[V_{t j}\right]}
$$

Estimation results for the MNL model are displayed in Table 4.

As expected, young customers are highly price sensitive, followed by standardticket buyers and subscribers. In addition, the price coefficient increases significantly when we consider popular productions as well as, surprisingly, performances that take place on Sunday.

With regard to the seat quality, the coefficients reflect an expected pattern: keeping the price fixed, an increase of the quality of the seat leads to a greater utility. This pattern holds for all the customer categories considered. Contrary to Baldin and Bille (2017), we can not compare the marginal utility of the seat categories across customers categories because each category has its own price coefficient. However, in terms of willingness to pay (WTP), i.e. the ratio between the coefficient of the attribute and the price coefficient, it results that this value is greater for subscribers, followed by standard-ticket buyers and young customers.

\section{$6 \mathrm{Bi}$-objective optimization of revenue and attendance}

The optimization model we propose considers the two objectives of the theater, i.e., to maximize revenue and attendance, in a constrained bi-objective maximization framework. It incorporates both the demand function and the customers' seat choices described in section 5 . The decision variables are the prices $p_{s j}$, for each seating area $s$ and each customer category $j$. As these prices affect the demand and the customers' seat choice, the optimal prices determine the optimal splitting into fare classes of the seats in the theater. 


\begin{tabular}{lll}
\hline & Coefficient & $t$-stat \\
\hline Price & $\mathbf{- 0 . 0 0 1 2 9} \mathbf{9}^{* * * *}$ & -11.88 \\
Price-Young & $-0.0109^{* * * *}$ & -26.32 \\
Price-Subscribers & $0.00074^{* * * *}$ & 3.87 \\
Price-popular Medium & 0.00005 & -1.03 \\
Price-popular high & $0.00036^{* * * *}$ & -1.93 \\
Price-Wkend & 0.00004 & 0.91 \\
Price-Sunday & $0.00023^{* * * *}$ & 5.55 \\
Seat 2 & $\mathbf{0 . 7 8 2}^{* * * *}$ & 28.93 \\
Seat 2 - Young & $0.427^{* * * *}$ & 7.09 \\
Seat 2 - Subscriber & 1.51 & 22.84 \\
Seat $\mathbf{3}$ & $\mathbf{1 . 3 7}^{* * * *}$ & 34.83 \\
Seat 3 - Young & $0.474^{* * * *}$ & 5.44 \\
Seat 3 - Subscriber & $1.56^{* * * *}$ & 18.78 \\
Seat 4 & $\mathbf{1 . 8 7}^{* * * *}$ & 36.04 \\
Seat 4 - Young & $1.12^{* * * *}$ & 9.81 \\
Seat 4 - Subscriber & $1.73^{* * * *}$ & 16.92 \\
Seat 5 & $\mathbf{1 . 9 5}^{* * * *}$ & 29.37 \\
Seat 5 - Young & $1.56^{* * * *}$ & 11.36 \\
Seat 5 - Subscriber & $1.86^{* * * *}$ & 14.58 \\
\hline No. of observations & & 103322 \\
$\rho^{2}$ & & 0.102 \\
Adjusted $\rho^{2}$ & & 0.102 \\
Null log-likelihood & & -166290.344 \\
Final log-likelihood & & -149291.813 \\
\hline$* * * * p<.001$ & &
\end{tabular}

Table 4: Estimation of multinomial logit model

The expected revenue and attendance can be written as, respectively,

$$
\text { Revenue }=\sum_{j=1}^{3} D_{j}\left(p_{j}\right) \cdot\left[\sum_{s=1}^{5} \operatorname{Pr}(s \mid j) \cdot p_{s j}\right]
$$

and

$$
\text { Attendance }=\sum_{j=1}^{3} D_{j}\left(p_{j}\right) \cdot\left[\sum_{s=1}^{5} \operatorname{Pr}(s \mid j)\right],
$$

where $D_{j}$ is the number of tickets sold to category $j$, defined by the estimated demand function (2); $p_{j}$ is the average price for a customer belonging to category $j ; \operatorname{Pr}(s \mid j)$ is the probability of buying a ticket of seating area $s$, given the customer category $j$, for the considered performance, as defined by (5). The maximum number of seats that can be sold is bounded by the capacity of the theater $C$ :

$$
\sum_{j=1}^{3} D_{j}\left(p_{j}\right) \cdot\left[\sum_{s=1}^{5} \operatorname{Pr}(s \mid j)\right] \leq C .
$$

Moreover, we have to consider a set of constraints that are required by the theater policy:

$$
p_{(s-1) j}<p_{s j}<p_{(s+1) j}, \quad \text { for each } j \text { and } s
$$


As seen in Section 4.1, both the ticket prices for a young customer and for a subscriber are obtained discounting the standard ticket price, given a seating area $s$.

However, we allow for a more flexible relationship:

$$
\begin{gathered}
0.4 \cdot p_{\text {standardticket }}<p_{\text {young }}<0.6 \cdot p_{\text {standardticket }}, \\
0.7 \cdot p_{\text {standardticket }}<p_{\text {subscriber }}<0.9 \cdot p_{\text {standardticket }} .
\end{gathered}
$$

Finally, we have the constraint that defines the relation between $p_{s j}$ and $p_{j}$

$$
p_{j}=\frac{1}{5} \sum_{s=1}^{5} p_{s j} .
$$

\section{Optimization results}

The bi-objective optimization model we defined consists in maximizing the two objectives, Revenue and Attendance, under the above defined constraints: the solution of such a problem is the set of Pareto optimal points, the so-called Pareto frontier of the problem. We observe that we are facing a nonlinear biobjective problem, due to the exponential term both in the demand function and in the formulation of the probability in the multinomial logit model. As usual in multi-objective optimization, in particular in the non-linear case, it is convenient to look for some points of the Pareto frontier; those points should be interesting from the point of view of the decision maker, in our case the direction of the theater.

We solved the problem by means of the Synchronous Approach adopted by Miettinen and Mäkelä (2006). Their model, called NIMBUS (Nondifferentiable Interactive Multiobjective BUndle-based optimization System), allows us to deal with nondifferentiable and nonconvex multiobjective optimization problems. The approach is based on the interaction between the decision maker and the solution algorithm, and is realized via the Internet based system WWWNIMBUS (https://wwwnimbus.it.jyu.fi). The single steps of the solution approach consist in the solution of single objective (sub)problems via classical subgradients methods (see, e.g., Clarke (1990)). Successive single optimisation subproblems are then solved under the guidance of the decision maker: each successive solution is a Pareto optimal solution of the multiobjective problem. At each iteration the decision maker can indicate the preferred way to navigate the set of Pareto optimal solutions, choosing the objectives whose value should be improved and, at the same time, which objectives should pay the cost of such improvement. In this way, the most appropriate solutions from the decision maker's point of view are selected from the Pareto optimal solutions set. The software is free for the academic community and is operated directly on the Internet site ${ }^{4}$, requiring neither the download of any software nor huge

\footnotetext{
4 https://wwwnimbus.it.jyu.fi
} 
computing capabilities of the client computer.

As case studies we consider three performances that differ by characteristics affecting the demand, to verify how different levels of theater occupancy require different pricing and allocation policies, in particular considering the peak-load pricing issue (i.e. differentiating prices charged depending on peak and off-peak periods). For the purpose of a better comparison between the actual pricing and allocation policies, and those resulting from the optimization model, we have chosen three performances that show a fitted value of the demand, which is very close to the real demand. The first performance is a high demand performance, namely a Saturday evening performance of La Tosca that fills up to $91.05 \%$ capacity. The second performance analyzed is a low demand performance, Djcevlene fra Loudun, run in a weekday: this performance fills less than half of the total capacity (41.98\%). The third performance is a medium-popular production, namely Rusalka, with $67.86 \%$ of the total capacity filled.

We are therefore able to compare the price ${ }^{5}$ and seat allocation results of the bi-objective optimization model with the actual results and also with those resulting from the two single objective optimization models: one that maximizes only the Revenue and one that maximizes only the total Attendance (see Tables 5-7).

Some remarks about the implementation of the models: first, for the purpose of realism we have established a lower and an upper bound to the 15 decision variables, respectively equal to the half and the double value of the actual price. Second, we subtract from the value of the capacity $C$ the number of tickets sold to other categories which were not considered, assuming it is already known by the theater manager.

Table 5 considers the results obtained for a Saturday evening performance of La Tosca. It is a high-demand event almost (but not completely) sold-out.

The bi-objective optimization model solutions shown in Table 5 (as well as all the other solutions shown in Table 6 and 7) represent one of the points of the Pareto frontier. Hence, there are other possible solutions. Figure 2 shows some alternative solutions of the bi-objective model. The solution proposed in Table 5 leads to an increment in revenue of $1.33 \%$ and a decrease of the total attendance of $16.65 \%$.

From Figure 2, the existence of a trade-off among the two objectives becomes evident: an increase in revenue is associated with a lower value of the attendance, and viceversa.

It is interesting to observe how price and seat allocation can change according to the orientation of the theater manager towards the two objectives. From Table 5 we can deduce that when the only objective is the maximization of the revenue, the theater exploits the inelasticity that characterizes subscribers and standard tickets buyers by increasing the price to the upper bound. As young customers are price sensitive, the corresponding price is increased until the loss of young customers is not more balanced by a higher revenue per seat. In the

${ }^{5}$ Price are expressed in Danish crown $(\mathrm{DKK}): 1 D K K \approx 0.13 e$ 


\begin{tabular}{lcccccccc}
\hline \multirow{2}{*}{ Seat } & \multicolumn{2}{c}{ Actual } & \multicolumn{2}{c}{ Bi-objective } & \multicolumn{2}{c}{ Revenue max. } & \multicolumn{2}{c}{ Attendance max. } \\
\cline { 2 - 9 } & Price & no. of seats & Price & no. of seats & Price & no. of seats & Price & no. of seats \\
\hline Seat1-standard & 160 & 46 & 300 & 59 & 320 & 67 & 176 & 60 \\
Seat2-standard & 345 & 79 & 341 & 123 & 690 & 105 & 399 & 108 \\
Seat3-standard & 525 & 144 & 625 & 173 & 1050 & 137 & 408 & 193 \\
Seat4-standard & 720 & 366 & 963 & 211 & 1440 & 160 & 536 & 285 \\
Seat5-standard & 895 & 258 & 1360 & 160 & 1710 & 136 & 565 & 301 \\
Seat1-young & 80 & 13 & 134 & 11 & 160 & 16 & 74 & 18 \\
Seat2-young & 173 & 23 & 170 & 24 & 299 & 10 & 172 & 19 \\
Seat3-young & 263 & 14 & 252 & 17 & 420 & 5 & 226 & 19 \\
Seat4-young & 360 & 14 & 386 & 11 & 576 & 2 & 294 & 27 \\
Seat5-young & 448 & 8 & 544 & 3 & 684 & 1 & 311 & 37 \\
Seat1-subscribers & 140 & 7 & 226 & 1 & 224 & 1 & 153 & 1 \\
Seat2-subscribers & 302 & 13 & 293 & 10 & 604 & 9 & 319 & 10 \\
Seat3-subscribers & 459 & 24 & 540 & 17 & 918 & 17 & 349 & 18 \\
Seat4-subscribers & 630 & 18 & 842 & 33 & 1260 & 31 & 428 & 35 \\
Seat5-subscribers & 783 & 42 & 1215 & 38 & 1539 & 37 & 497 & 43 \\
\hline Total & 682118 & 1069 & 691167 & 891 & 826714 & 733 & 529468 & 1174 \\
\% improve (Revenue and attendance) & & & +1.33 & -16.65 & +21.20 & -31.43 & -22.38 & +9.83 \\
\hline
\end{tabular}

Table 5: Revenue and attendance comparison. Case study: La Tosca, season 2014-2015

BAR CHARTS ARRANGED BY ALTERNATIVE (Relative values) Different alternatives have different colours

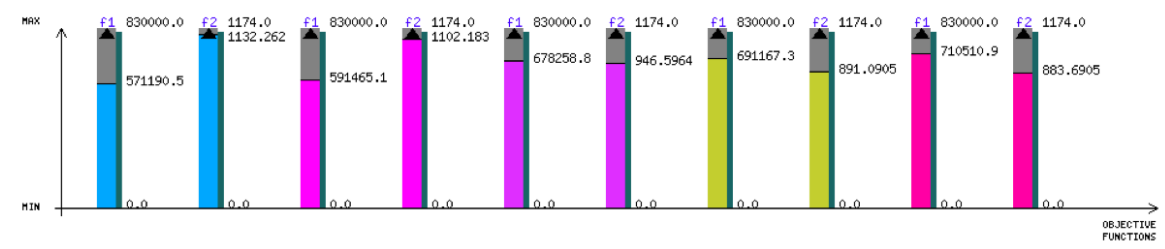

Fig. 2: Some alternative optimal values of the bi-objective model. Source: https://wwwnimbus.it.jyu.fi/

attendance maximization perspective, since the performance almost reaches the capacity constraint, the objective is achieved by lowering only the prices of the most expensive seat category.

In relation to the allocation policy, we notice that when the theater is "attendance maximizer" customers are more likely to shift to a higher seat quality (buy-up behavior) as a consequence of a generalized price reduction. Viceversa, if the theater is "revenue maximizer", customers are more likely to buy a ticket for a cheap seat because they are not willing to pay more. This behavior is evident when we refer to price sensitive customers. On the contrary, price insensitive customers are not influenced by the theater policy in their choice of the seating area, which is confirmed in Figures 3 and 4 - respectively for young customers and subscribers - showing how the probability of buying a ticket of certain seating areas changes according to the theater policy. Thus, the optimal pricing and allocation policy depends on the type of customers the theater expects to accomodate.

Table 6 considers the results obtained for a weekday performance of Djacvlene fra Loudun. It is a low-demand event in which the theater is usually 


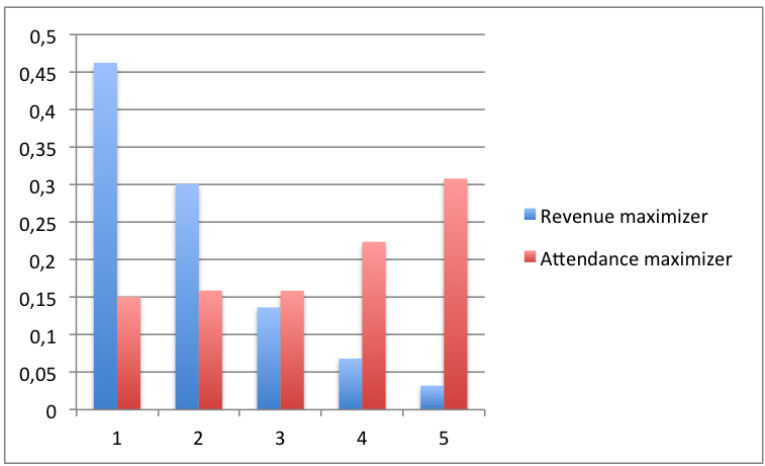

Fig. 3: Young customers' choice probabilities

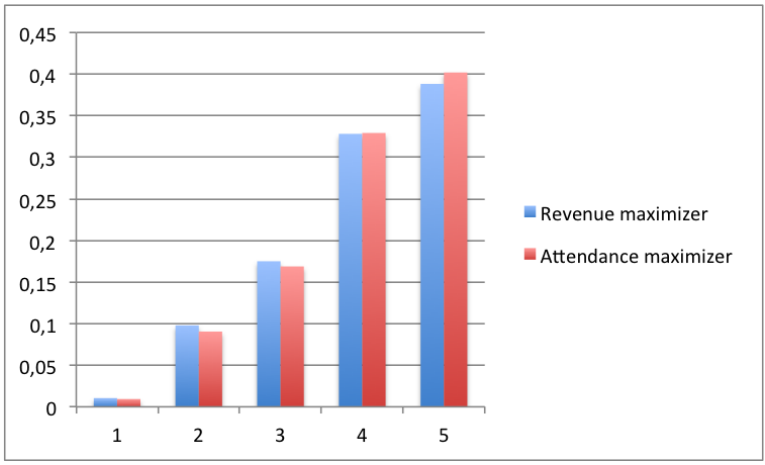

Fig. 4: Subscribers' choice probabilities

occupied approximately only a little bit more than a third of its capacity. One solution obtained solving the bi-objective model allows an increase in attendance of $13.26 \%$ while requiring a decrease in revenue of $12.25 \%$. Compared to the previous case, here the theater is forced to reduce prices to the lower bound when it aims to maximize attendance.

Concerning the allocation policy, the pattern previously described is even more evident as the price coefficient of the MNL model decreases when a non popular event is considered. Hence, if the theater is "attendance" (revenue) maximizer, the suggestion is to increase(decrease) the size of the most expensive (cheapest) seating area, especially when theater expects to attract a price-insensitive audience group (as young customers).

Table 7 considers the results obtained for a Sunday performance of Rusalka. This is an intermediate case compared to the previous two. This case is interesting as the bi-optimization model provides a solution that dominates the current value of the objectives. Indeed, the solution proposed allows an increase in revenue of $1.90 \%$ and, at the same time, an increase in attendance of $1.83 \%$. 


\begin{tabular}{lcccccccc}
\hline \multirow{2}{*}{ Seat } & \multicolumn{2}{c}{ Actual } & \multicolumn{2}{c}{ Bi-objective } & \multicolumn{2}{c}{ Revenue max. } & \multicolumn{2}{c}{ Attendance max. } \\
\cline { 2 - 9 } & Price & no. of seats & Price & no. of seats & Price & no. of seats & Price & no. of seats \\
\hline Seat1-standard & 160 & 41 & 110 & 12 & 320 & 8 & 80 & 13 \\
Seat2-standard & 295 & 23 & 216 & 24 & 590 & 20 & 148 & 26 \\
Seat3-standard & 425 & 29 & 366 & 36 & 850 & 26 & 213 & 44 \\
Seat4-standard & 545 & 50 & 505 & 50 & 1090 & 31 & 307 & 66 \\
Seat5-standard & 695 & 42 & 560 & 50 & 1352 & 24 & 348 & 69 \\
Seat1-young & 80 & 16 & 47 & 9 & 160 & 6 & 40 & 9 \\
Seat2-young & 148 & 11 & 91 & 17 & 277 & 4 & 74 & 21 \\
Seat3-young & 213 & 1 & 148 & 16 & 340 & 4 & 107 & 56 \\
Seat4-young & 273 & 9 & 202 & 27 & 436 & 4 & 137 & 62 \\
Seat5-young & 348 & 3 & 226 & 33 & 541 & 2 & 174 & 2 \\
Seat1-subscribers & 140 & 3 & 79 & 2 & 224 & 3 & 70 & 22 \\
Seat2-subscribers & 258 & 11 & 162 & 23 & 516 & 23 & 129 & 22 \\
Seat3-subscribers & 372 & 13 & 287 & 41 & 744 & 38 & 186 & 41 \\
Seat4-subscribers & 551 & 86 & 443 & 74 & 981 & 67 & 276 & 79 \\
Seat5-subscribers & 608 & 107 & 503 & 88 & 1216 & 72 & 304 & 97 \\
\hline Total & 209268 & 445 & 183420 & 504 & 302384 & 331 & 144313 & 637 \\
\% improve (Revenue and attendance) & & & -12.35 & +13.26 & +44.50 & -25.61 & -31.04 & +43.15 \\
\hline
\end{tabular}

Table 6: Revenue and attendance comparison. Case study: Djcevlene fra

Loudun, season 2012-2013

\begin{tabular}{lcccccccc}
\hline \multirow{2}{*}{ Seat } & \multicolumn{2}{c}{ Actual } & \multicolumn{2}{c}{ Bi-objective } & \multicolumn{2}{c}{ Revenue max. } & \multicolumn{2}{c}{ Attendance max. } \\
\cline { 2 - 9 } & Price & no. of seats & Price & no. of seats & Price & no. of seats & Price & no. of seats \\
\hline Seat1-standard & 160 & 43 & 172 & 35 & 320 & 40 & 84 & 39 \\
Seat2-standard & 345 & 70 & 292 & 68 & 692 & 59 & 204 & 75 \\
Seat3-standard & 525 & 72 & 619 & 88 & 1052 & 74 & 315 & 120 \\
Seat4-standard & 720 & 150 & 740 & 129 & 1440 & 83 & 408 & 181 \\
Seat5-standard & 895 & 109 & 782 & 134 & 1743 & 66 & 483 & 182 \\
Seat1-young & 80 & 6 & 79 & 8 & 160 & 7 & 45 & 9 \\
Seat2-young & 173 & 18 & 127 & 15 & 301 & 4 & 92 & 17 \\
Seat3-young & 263 & 7 & 249 & 6 & 423 & 2 & 183 & 11 \\
Seat4-young & 360 & 8 & 296 & 12 & 580 & 1 & 184 & 35 \\
Seat5-young & 448 & 2 & 420 & 4 & 702 & 0 & 224 & 36 \\
Seat1-subscribers & 140 & 19 & 149 & 5 & 224 & 5 & 71 & 5 \\
Seat2-subscribers & 302 & 27 & 259 & 44 & 622 & 43 & 151 & 45 \\
Seat3-subscribers & 459 & 35 & 542 & 76 & 920 & 74 & 266 & 82 \\
Seat4-subscribers & 630 & 163 & 639 & 146 & 1260 & 134 & 322 & 160 \\
Seat5-subscribers & 783 & 175 & 703 & 177 & 1568 & 152 & 397 & 194 \\
\hline Total & 550190 & 929 & 560664 & 946 & 874000 & 745 & 394026 & 1191 \\
\% improve (Revenue and attendance) & & & +1.90 & +1.83 & +58.85 & -19.91 & -28.38 & +28.20 \\
\hline
\end{tabular}

Table 7: Revenue and attendance comparison. Case study: Rusalka, season 2013-2014

\section{Conclusions}

This paper has proposed a model that simultaneously optimizes the pricing and seating-allocation policy of a theater. In particular, we present a bi-objective optimization model that integrates the demand forecast and a choice model, where the customer chooses one among different seating areas which differ in price and quality. The multi-objective nature of our model reflects the multidimensional nature of nonprofit performing arts organizations. In our case, the objectives we assume to be maximized are revenue and attendance. The approach adopted also allows to take into account heterogeneity in price sensitivity and choice behavior across different customer segments. The proposed model is applied to booking data provided by the Royal Danish theater re- 
ferring to the period 2010-2015. More precisely, we consider three different performances in order to explore the potentialities of the model.

From a managerial perspective, the model can provide theater managers with insightful policy implications in terms of demand-management decisions. The results obtained confirm the existence of a trade-off between the two theater objectives. When the theater is "revenue maximizer", prices charged to price insensitive customers are raised, and the cheapest seating area is enlarged to prevent a loss of revenue. Viceversa, when the theater is audience maximizer, prices are set at lower levels, in particular the ones associated to the most expensive seating area. As a consequence, it is recommended to increase the number of seats allocated to the most expensive area, in order to encourage a shift of customer choices to higher quality seats. The allocation policy just described is particularly effective when a performance is expected to attract customers with an elastic demand, since they are more sensitive to price changes in their seat choice; and also when the performance will probably not attract a large audience. Moreover, in one case the bi-objective model provides a solution that causes an improvement in both revenue and attendance from the current situation.

Overall, our examples clarify that both price and capacity allocation are leverages with which a theater can calibrate its objectives, even when revenue is not considered as the main goal to pursue.

\section{References}

Ainslie A, Drèze X, Zufryden F (2005) Modeling movie life cycles and market share. Marketing Science 24(3):508-517

Andrews RL, Currim IS, Leeflang P, Lim J (2008) Estimating the scan pro model of store sales: $\mathrm{Hb}$, fm or just ols? international Journal of research in marketing 25(1):22-33

Baldin A, Bille T (2017) Modelling preference heterogeneity for theatre tickets: a discrete choice modelling approach on royal danish theatre booking data. Applied Economics pp 1-14

Baumol WJ, Bowen WG (1966) Performing Arts-the Economic Dilemma: A Study of Problems Common to Theatre, Opera, Music and Dance. MIT Press

Brooks AC (2006) Nonprofit firms in the performing arts. Handbook of the Economics of Art and Culture 1:473-506

Clarke FH (1990) Optimization and nonsmooth analysis. SIAM

Corning J, Levy A (2002) Demand for live theater with market segmentation and seasonality. Journal of Cultural Economics 26(3):217-235

Eliashberg J, Hegie Q, Ho J, Huisman D, Miller SJ, Swami S, Weinberg CB, Wierenga B (2009) Demand-driven scheduling of movies in a multiplex. International Journal of Research in Marketing 26(2):75-88

Felton MV (1994) Evidence of the existence of the cost disease in the performing arts. Journal of Cultural Economics 18(4):301-312 
Gapinski JH, et al (1985) Do the nonprofit performing arts optimize? the moral from shakespeare. Quarterly Review of Economics and Business 25(2):27-37

Hansen TB (1991) Det Kgl. Teater: et kulturøkonomisk studie. AKF

Hansmann H (1981) Nonprofit enterprise in the performing arts. The Bell Journal of Economics pp 341-361

Hansmann HB (1980) The role of nonprofit enterprise. The Yale law journal 89(5):835-901

Hetrakul P, Cirillo C (2014) A latent class choice based model system for railway optimal pricing and seat allocation. Transportation Research Part E: Logistics and Transportation Review 61:68-83

Huntington PA (1993) Ticket pricing policy and box office revenue. Journal of Cultural Economics 17(1):71-87

Laamanen JP (2013) Estimating demand for opera using sales system data: the case of finnish national opera. Journal of Cultural Economics 37(4):417-432

Leslie P (2004) Price discrimination in broadway theater. RAND Journal of Economics pp 520-541

Luksetich WA, Lange MD (1995) A simultaneous model of nonprofit symphony orchestra behavior. Journal of Cultural Economics 19(1):49-68

Marco-Serrano F (2006) Monitoring managerial efficiency in the performing arts: A regional theatres network perspective. Annals of Operations Research 145(1):167-181

Miettinen K, Mäkelä MM (2006) Synchronous approach in interactive multiobjective optimization. European Journal of Operational Research 170(3):909 922

Rosen S (1974) Hedonic prices and implicit markets: product differentiation in pure competition. Journal of political economy 82(1):34-55

Rosen S, Rosenfield AM (1997) Ticket pricing 1. The Journal of Law and Economics 40(2):351-376

Seaman BA (1985) Price discrimination in the arts. Managerial Economics for the Arts Association for Cultural Economics, University of Akron pp 47-60

Seaman BA (2006) Empirical studies of demand for the performing arts. Handbook of the economics of art and culture 1:415-472

Steinberg R (1986) The revealed objective functions of nonprofit firms. The RAND Journal of Economics pp 508-526

Talluri K, Van Ryzin G (2004) Revenue management under a general discrete choice model of consumer behavior. Management Science 50(1):15-33

Talluri KT, Van Ryzin GJ (2006) The theory and practice of revenue management, vol 68. Springer Science \& Business Media

Tereyagoglu N, Fader P, Veeraraghavan S (2012) Filling seats at a theater: Estimating the impact of posted prices and dynamic discounts. The Wharton School, University of Pennsylvania, Philadelphia, PA 19104

Throsby CD, Withers GA, et al (1993) The economics of the performing arts. Gregg Revivals

Throsby D (1994) The production and consumption of the arts: A view of cultural economics. Journal of economic literature 32(1):1-29 